\title{
The Effect of Telephone Follow-Up on Quality of Life in Hemodialysis
}

\section{Patients}

\author{
Seyed Reza Borzou ${ }^{1}$, Nahideh Babaei ${ }^{2}$, Mahmood Gholyaf ${ }^{3}$, Mehdi Molavi Vardanjani (iD ${ }^{1,{ }^{*}}$ and Leili \\ Tapak $^{4}$ \\ ${ }^{1}$ Research Center for Chronic Diseases (Home Care), Faculty of Nursing and Midwifery, Hamadan University of Medical Sciences, Hamadan, Iran \\ ${ }^{2}$ Student Research Committee, Faculty of Nursing and Midwifery, Hamadan University of Medical Sciences, Hamadan, Iran \\ ${ }^{3}$ Department of Internal Medicine, Urology and Nephrology Research Center, Shahid Beheshti Medical Educational Center, School of Medicine, Hamadan University of \\ Medical Sciences, Hamadan, Iran \\ ${ }^{4}$ Department of Biostatistics, School of Public Health, Hamadan University of Medical Sciences, Hamadan, Iran \\ "Corresponding author: Research Center for Chronic Diseases (Home Care), Faculty of Nursing and Midwifery, Hamadan University of Medical Sciences, Hamadan, Iran. Email: \\ m.molavi@umsha.ac.ir
}

Received 2020 April 27; Accepted 2020 May 09.

\begin{abstract}
Background: Problems with dialysis cause dramatic changes in these patients. Treatment of dialysis patients without the patient's participation and self-care activities cannot be effective enough.

Objectives: The aim of this study was to investigate the effect of telephone follow-up care on the quality of life of hemodialysis patients.

Methods: This clinical trial was performed on 60 hemodialysis patients in Hamedan, in two groups of tests and controls in 2018. Both groups of patients benefited from routine care and training in the ward, and then, in the test group, these patients were followed up by telephone for 6 weeks. The KDQOL-SF (short form) Demographic and Quality of Life questionnaire was used before and after the intervention to collect data. Data analysis was performed using SPSS 16 software using a $t$-test, paired $t$-test, and chi-square test.

Results: The mean and standard deviation of quality of life in the experimental group changed from $52.33 \pm 14.37$ to $57.89 \pm 12.02$ and in the control group from $52.62 \pm 13.05$ to $41.85 \pm 0.23$ that indicates there was a significant increase in the quality of life of hemodialysis patients in the experimental group. The results showed that the average difference in quality of life after the intervention in the experimental group in terms of understanding public health $(\mathrm{P}=0.002)$, physical performance $(\mathrm{P}=0.002)$, symptoms and signs of the disease $(\mathrm{P}<0.001)$ area of the disease, $(\mathrm{P}=0.012)$, pain $(\mathrm{P}<0.001)$, social support $(\mathrm{P}<0.001$ and general health $(\mathrm{P}$ $<0.001)$ were significant.

Conclusions: According to the findings of the study, it can be concluded that telephone follow-up care has been effective on the quality of life of hemodialysis patients.
\end{abstract}

Keywords: Phone Follow-Up Care, Quality of Life, Hemodialysis

\section{Background}

One of the most common and effective methods of treatment for patients with chronic renal failure is hemodialysis (1). Hemodialysis is a treatment for the removal of excess toxins, such as uremic toxins from the blood, as well as the regulation of electrolyte concentrations and the removal of excess water (2). Hemodialysis can dramatically alter the lives of patients, including improvement in the reduced efficiency and ability to function, weakness, fatigue, social isolation, inactivity, low selfesteem, and, ultimately frustration with the future. The presence of these conditions affects the health status and roles of the individual and, over time reduces their quality of life. Numerous problems with treatment and long-term dependence on hemodialysis reveal the need to pay attention to the quality of life of these patients (3).

Quality of life is a concept that includes a sense of wellbeing, both physically and mentally, and can be influenced by one's individual, social, and clinical characteristics, as well as one's experience and understanding of life. On the other hand, chronic diseases with the effect they have on the patient's health will eventually lead to adverse effects on the patient's quality of life (4). Studies show that the quality of life in patients treated with hemodialysis is lower than in the general population. In a study conducted 
by Abbaszadeh et al. (5) on the quality of life of hemodialysis and kidney transplant patients, hemodialysis patients, compared to transplant patients, had low quality of life in all aspects. The primary and important goal of treatment in these patients is to enhance the quality of life by reducing the effects of the disease (6).

The shortage of nursing staff, the increase in chronic diseases, the growth of the world's elderly population, the management of cost reduction, the geographical distance of many patients from care centers, and the change in health policies have led to the formation of home care and subsequent nursing. (7). In remote nursing, the key factor in the success of patient monitoring is the use of a device that is available, the user is fully familiar with it, and no software training is required (8).

\section{Objectives}

Therefore, considering the importance of following up on chronic patients and the high cost of the face-to-face method, the present study was conducted to determine the effect of follow-up telephone care on the quality of life of hemodialysis patients.

\section{Methods}

The present study is a quasi-experimental, before and after method. The research population was patients undergoing hemodialysis who refer to the hemodialysis training centers in Hamedan between 2017-2018. Sampling was performed by availability. To determine the required sample size at the $95 \%$ confidence level and the $80 \%$ test power, after quantifying the sample size formula, 30 people were estimated to be required in each group. Of these, two of the kidney transplant samples, three died, and one sample was removed from the study more than twice in a row due to not receiving the text message. In the end, the study was performed on 54 people. In order to prevent information pollution, the Besat Hospital was selected as the test group, and the Shahid Beheshti Hospital was selected by the control group.

Inclusion criteria consist of 18 to 65 years of age, a history of hemodialysis for at least 6 months, hemodialysis 2 or 3 times a week for 3 or 4 hours each time, no mental health problems or functional disability (by reviewing patient medical record), literacy, having a mobile phone in person and having the necessary ability to use the mobile phone and reading text messages, listening-speaking ability, acceptable alertness to answer questions, willingness to participate in the study. Exclusion criteria the study include not wanting to continue participating in the study, not receiving text messages more than twice in a row, death, kidney transplantation, and simultaneous participation in a similar study.

The data collection tool in this study was the personal profile form and the quality of life questionnaire of dialysis patients. The KDQOL-SF (Kidney disease quality of life) questionnaire was developed in 1994 by Hays et al. (9). The questionnaire is a standardized tool that includes 7 subscales of health-related quality of life and 11 subscales of specific quality of life for kidney disease. The subscale of the Health-Related Life Quality scale, which is the general core of the questionnaire, is the 36-item questionnaire (sf-36). This tool has 7 general dimensions, which include: physical function (10 questions), limitation of the role created by physical problems (4 questions), limitation of the role created by emotional problems (3 questions), social performance (2 questions), and sense of well-being. Emotional-fatigue and energy (9 questions), pain (2 questions), the field of understanding public health (6 questions). The specific dimension of the research instrument includes 46 questions and 11 areas including symptoms and problems (12 questions), the impact of kidney disease on life (8 questions), the burden of kidney responsibility (4 questions), the quality of social interaction (3 questions) and cognitive function (3 questions), family satisfaction related to health (2 questions), sleep status (4 questions), job status (2 questions), sexual performance (2 questions), social support (2 questions), satisfaction with the care of friends and staff (3 questions) is a question in hemodialysis and general health patients. The estimated time to answer the questions in this questionnaire is 20 - 30 minutes. Each domain has 100 points, which shows higher scores in all aspects of a better quality of life. The validity and reliability of this questionnaire in dialysis patients in Iran have been studied by Yekaninejad et al. (10). Taheri (11) used this questionnaire in 2011 in Abadan and Khoramshahr to determine the quality of life of dialysis patients. Therefore, in the present study, the above tool was used with the permission of Dr. Taheri, without the need for validity and reliability.

After the necessary coordination with the hemodialysis departments of Hamadan University of Medical Sciences, and the selection of participants while introducing themselves to patients, the researcher explained the objectives of the research and by obtaining conscious consent from the participants, while assuring them that their information was completely confidential; and they could get out of the study whenever they want. The patient's mobile phone was examined by the researcher to ensure that the patient was able to read the Persian message and read the messages.

At the beginning of the study, the Demographic ques- 
tionnaire and the Quality of Life questionnaire (KDQOL-SF) were completed in both groups. In the test group, based on the needs of patients, according to the information obtained from the questionnaire (KDQOL-SF), the content of the text message was prepared by the research group based on authoritative scientific books and resources in this field $(12,13)$ and the nephrologist. It was reviewed and approved. The researcher sends short messages about behaviors related to accepting treatment and quality of life, including (responsibility for illness, diet, and limiting fluid intake, exercise and physical activity, vascular care and infection control, medication regimen, prevention methods, and so on. To eliminate the effects of the disease. At least 6 text messages were sent to the research units each week, and a total of 80 text messages were sent in 6 weeks. The researcher sent these text messages with his personal mobile phone, and the text messages were in Persian. Each SMS was given a number, and for each message sent to each patient, a message was sent in front of the message. If the SMS was not sent to the research unit more than twice in a row, his landline would be called, and the cause would be investigated, and if necessary, another mobile number would be received from the patient and text messages would be sent to the new patient number. If the patient did not want to continue the cooperation, they would be excluded from the study. The research units noted that telephone follow-up for questions, ambiguities, and problems was free so that patients could contact the researcher by phone or text message and provide them with the necessary information. After 6 weeks, the text message was stopped via a mobile phone. In the end, one and a half months after the intervention, during the previous coordination and a telephone call with the participants, they were asked to go to the medical center at the appointed days and hours, and fill again the KDQOL-SF quality of life questionnaire. Finally, the data were analyzed using chi-square test, independent $t$-test and paired $t$-test using 22 SPSS statistical software at a significance level of $\mathrm{P}<0.05$.

\section{Results}

In this study, data analysis showed that the two groups of test and control in terms of gender, age, marital status, job status, education, frequency of dialysis, cause of dialysis, smoking and type of insurance using statistical test of chi-square. No difference was observed, and the two groups were the same in terms of these contextual variables (Table 1).

Data from the hemodialysis patients; Quality of Life questionnaire showed that before the intervention of the two groups of test and control, there was no statistically significant difference in the quality of life. In comparing

\begin{tabular}{|c|c|c|c|}
\hline Variable & Intervention G & Control G & $\begin{array}{l}\text { PValue; } \\
\text { Chi-Square }\end{array}$ \\
\hline Sex & & & 1 \\
\hline Male & $18(60)$ & $18(60)$ & \\
\hline Female & $12(40)$ & $12(40)$ & \\
\hline Marital status & & & 1 \\
\hline Single & $7(23.3)$ & $7(23.3)$ & \\
\hline Married & $23(76.7)$ & $23(76.7)$ & \\
\hline Occupation & & & 0.899 \\
\hline $\begin{array}{l}\text { Unem- } \\
\text { ployed }\end{array}$ & $5(16.7)$ & $7(23.3)$ & \\
\hline Employed & $3(10)$ & $4(13.3)$ & \\
\hline Retired & $4(13.3)$ & $2(6.7)$ & \\
\hline $\begin{array}{l}\text { The number of } \\
\text { dialysis times }\end{array}$ & & & 0.706 \\
\hline $\begin{array}{l}2 \text { times a } \\
\text { week }\end{array}$ & $5(16.7)$ & $3(10)$ & \\
\hline $\begin{array}{l}3 \text { times a } \\
\text { week }\end{array}$ & $25(83.3)$ & $27(90)$ & \\
\hline $\begin{array}{l}\text { The cause of } \\
\text { dialysis }\end{array}$ & & & 0.099 \\
\hline DM & $8(26.7)$ & $15(50)$ & \\
\hline $\begin{array}{l}\text { Hyperten- } \\
\text { sion }\end{array}$ & $13(43.3)$ & $6(20)$ & \\
\hline $\begin{array}{l}\text { Underlying } \\
\text { disease }\end{array}$ & $9(30)$ & $9(30)$ & \\
\hline
\end{tabular}

${ }^{\mathrm{a}}$ Values are expressed as No. (\%).

the average scores of total quality of life, before and after the intervention in both groups, the independent $t$ test showed deleted increased and changed in the control group from $52.62 \pm 13$ to $41.85 \pm 0.23$ and in intervention group from $52.33 \pm 14.37$ to $57.89 \pm 12.02$, indicating a significant increase in the quality of life of hemodialysis patients in the experimental group. In intragroup comparisons, quality of life in terms of public health, physical function, physical pain, symptoms, and problems of the disease, the impact of kidney disease, social support, and general health after intervention in the intervention group showed significant statistical improvement $(\mathrm{P}<$ 0.05). However, no statistically significant differences were observed in the other dimensions (Table 2).

\section{Discussion}

The results of the present study showed an increase in the overall score of quality of life after the intervention in the test group. According to research conducted on different diseases and with different methods, the results of the 


\begin{tabular}{|c|c|c|c|}
\hline Variable & $\begin{array}{c}\text { Before } \\
\text { Intervention }\end{array}$ & $\begin{array}{c}\text { After } \\
\text { Intervention }\end{array}$ & $\mathbf{P}^{\mathbf{b}}$ \\
\hline \multicolumn{4}{|l|}{$\begin{array}{l}\text { Understand } \\
\text { public health }\end{array}$} \\
\hline $\begin{array}{l}\text { Interven- } \\
\text { tion }\end{array}$ & $49.16 \pm 16.40$ & $55.12 \pm 66.08$ & 0.03 \\
\hline Control & $48.18 \pm 50.80$ & $37.15 \pm 50.19$ & 0.73 \\
\hline$P^{c}$ & 0.24 & 0.06 & \\
\hline \multicolumn{4}{|l|}{$\begin{array}{l}\text { Physical } \\
\text { performance }\end{array}$} \\
\hline $\begin{array}{l}\text { Interven- } \\
\text { tion }\end{array}$ & $18 \pm 64.16$ & $70.17 \pm 16.64$ & 0.002 \\
\hline Control & $57.19 \pm 83.05$ & $56.20 \pm 66.19$ & 0.939 \\
\hline $\mathrm{P}^{\mathrm{c}}$ & 0.205 & 0.011 & \\
\hline \multicolumn{4}{|l|}{$\begin{array}{l}\text { Role constraints } \\
\text { due to physical } \\
\text { problems }\end{array}$} \\
\hline $\begin{array}{l}\text { Interven- } \\
\text { tion }\end{array}$ & $30.26 \pm 74.66$ & $35.35 \pm 71$ & 0.067 \\
\hline Control & $37.27 \pm 34.50$ & $35.19 \pm 33.79$ & 0.44 \\
\hline $\mathrm{P}^{\mathrm{c}}$ & 0.925 & 0.124 & \\
\hline \multicolumn{4}{|l|}{ mental health } \\
\hline $\begin{array}{l}\text { Interven- } \\
\text { tion }\end{array}$ & $36.40 \pm 66.44$ & $47.41 \pm 77.69$ & 0.86 \\
\hline Control & $52.22 \pm 44.36$ & $52.77 \pm 47.05$ & 0.52 \\
\hline $\mathrm{P}^{\mathrm{c}}$ & 0.161 & 0.681 & \\
\hline \multicolumn{4}{|l|}{ Physical pain } \\
\hline $\begin{array}{l}\text { Interven- } \\
\text { tion }\end{array}$ & $55.22 \pm 16.20$ & $67.18 \pm 83.75$ & $<0.001$ \\
\hline Control & $58.25 \pm 66$ & $24 \pm 60.41$ & 0.72 \\
\hline $\mathrm{P}^{\mathrm{c}}$ & 0.569 & 0.188 & \\
\hline \multicolumn{4}{|l|}{$\begin{array}{l}\text { Emotional } \\
\text { domain }\end{array}$} \\
\hline $\begin{array}{l}\text { Interven- } \\
\text { tion }\end{array}$ & $55.13 \pm 92.66$ & $56.13 \pm 44.43$ & 0.834 \\
\hline Control & $56.16 \pm 59.74$ & $56.13 \pm 66.93$ & 0.795 \\
\hline $\mathrm{P}^{\mathrm{c}}$ & 0.866 & 0.953 & \\
\hline \multicolumn{4}{|l|}{$\begin{array}{l}\text { Area social } \\
\text { performance }\end{array}$} \\
\hline $\begin{array}{l}\text { Interven- } \\
\text { tion }\end{array}$ & $57.19 \pm 91.27$ & $62.19 \pm 50.96$ & 0.148 \\
\hline Control & $64.20 \pm 58.78$ & $65.21 \pm 62.88$ & 0.728 \\
\hline $\mathrm{P}^{\mathrm{c}}$ & 0.203 & 0.586 & \\
\hline
\end{tabular}

${ }^{\mathrm{a}}$ Values are expressed as mean $\pm \mathrm{SD}$.

${ }^{\mathrm{b}}$ Paired $t$-test.

${ }^{\mathrm{c}}$ Independent $t$-test.

present study are in accordance with Sadeghi et al. (14) (diabetes for three months with 16 telephone follow-ups) and the study of Sadeghisherme et al. (15) with the aim of following the effect of telephone care and SMS on patients' quality of life after coronary artery bypass graft surgery in Tehran.

Another study by Victoria et al. (16) Aimed at the influence of nursing counseling and active patient participation in clinical decision-making to improve treatment adherence to the quality of life of patients undergoing hemodialysis using the Mysola questionnaire in Greece, despite differences in duration and the type of intervention, it was consistent with the present study. They used counseling, pamphlets, and instructional videos in their educational interventions, and the results showed that education significantly improved the quality of life of these patients (16).

In a health study, Salimi Ezzat et al. (17) conducted a total of 28 telephone follow-ups for 12 weeks with the aim of influencing counseling and telephone follow-up on medical follow-up and dialysis adequacy in patients under chronic hemodialysis using a questionnaire(ESRD-AQ). The results showed that telephone counseling and followup improved follow-up of the treatment regimen (17).

Gallar et al. (18) In Spain studied the benefits of telemedicine dialysis using a video conference device to monitor blood pressure, edema, medications, catheterization, and fluid intake at home via follow-up through the virtual system.

Another study by Wells (19) In the United States found that training in chronic patients increased awareness. However, these researchers noted that increased awareness did not affect the rate of adherence to the treatment regimen (19).

Perhaps the reason for the difference between the present study and the Wells study (19) is the effect of telephone follow-up care. Normal care will be more effective when nurses continue to follow up on these patients (19). Therefore, in this study, what has improved the quality of life is, in fact, the telephone follow-up by the nurse and support in the areas of self-care in the form of texting to remind. Since the patient easily forgets the instructions given, repeating and reminding the important points at regular intervals and following up by phone will make the patient not forget the contents and provide him with services based on the patient's needs. Studies have shown that transfer care, such as providing hospital-to-home counseling by telephone, has a positive effect on patients with chronic diseases and has led to changes in health and behaviors in these patients. Also, those who followed up by phone made significant progress compared to those who had regular care (20).

Limitations of this research include low sample size, different psychological characteristics, individual differences of the studied units. Assessing the effect of telephone follow-up care in other chronic diseases in different situations and with a larger sample size and more frequent check time is suggested.

\subsection{Conclusions}

Follow-up telephone care increases the quality of life of patients undergoing hemodialysis due to nonexistence 
of time and space restrictions, absence of need for travel and additional costs, and timely access to information and training of care items. To this end, it is suggested that clinics and health centers use telephone follow-up care using the experiences of nurses and landlines for training, counseling, follow-up, and answering possible questions of patients with chronic diseases such as kidney failure. Due to the increasing number of people with kidney failure in the community and their constant need for education, counseling, and follow-up, telephone follow-up care can be used as a system to provide health care services in dealing with chronic patients, especially kidney failure.

\section{Acknowledgments}

The present article is the result of a Master's thesis in nursing. The authors thank the Vice Chancellor for Research and Technology and the Research Council of Hamadan University of Medical Sciences, the staff of the Hemodialysis ward, and the patients who helped us carry out this project.

\section{Footnotes}

Authors' Contribution: Seyed Reza Borzou, Mahmood Gholyaf and Mehdi Molavi Vardanjani designed the study. Nahideh Babaei collected data. Leili Tapak analysed data.

Clinical Trial Registration Code: The clinical trial registration code was IRCT20160110025929N8.

Conflict of Interests: There is no conflict of interest of authors of this manuscript.

Ethical Approval: The code of ethics was IR.UMSHA.REC.1396.569 in the Clinical Trials Center of the Ministry of Health.

Funding/Support: Vice Chancellor for Research and Technology, Hamadan University of Medical Sciences funded this research (code: 9609075533).

\section{References}

1. Ramirez SP, Macedo DS, Sales PM, Figueiredo SM, Daher EF, Araujo $\mathrm{SM}$, et al. The relationship between religious coping, psychological distress and quality of life in hemodialysis patients. J Psychosom Res. 2012;72(2):129-35. doi: 10.1016/j.jpsychores.2011.11.012. [PubMed: 22281454].

2. Kashiwagi T, Sato K, Kawakami S, Kiyomoto M, Enomoto M, Suzuki T, et al. Effects of reduced dialysis fluid flow in hemodialysis. J Nippon Med Sch. 2013;80(2):119-30. doi: 10.1272/jnms.80.119. [PubMed: 23657065].

3. Rayner HC, Zepel L, Fuller DS, Morgenstern H, Karaboyas A, Culleton $\mathrm{BF}$, et al. Recovery time, quality of life, and mortality in hemodialysis patients: The Dialysis Outcomes and Practice Patterns Study (DOPPS). Am J Kidney Dis. 2014;64(1):86-94. doi: 10.1053/j.ajkd.2014.01.014. [PubMed: 24529994]. [PubMed Central: PMC4069238].
4. Ouzouni S, Kouidi E, Sioulis A, Grekas D, Deligiannis A. Effects of intradialytic exercise training on health-related quality of life indices in haemodialysis patients. Clin Rehabil. 2009;23(1):53-63. doi: 10.1177/0269215508096760. [PubMed: 19114437].

5. Abbaszadeh A, Javanbakhtian R, Salehee S, Motvaseliyan M. [Comparative assessment of quality of life in hemodialysis and kidney transplant patients]. J Shahid Sadoughi Univ Med Sci. 2010;18(5):461-8. Persian.

6. Alijany-Renany H, Tamaddoni A, Haghighy-zadeh M, Pourhosein S. The effect of using partnership care model on the quality of life in the school-age children with $\beta$-thalassemia.J Shahrekord Univ Med Sci. 2012;14(1):41-9.

7. Fakharzadeh L, Shahbazian H, Salehinia H, Yaghoobi M, Haghighizadeh M, Karandish M. [Effect of telenursing on glycosylated hemoglobin (HbA1c) and anthropometric indexes in type 2 diabetic patients]. Mod Care J. 2013;10(2):101-7. Persian.

8. Sadeghi T, Shahabinejad M, Derakhshan R, Balaii P. Effect of nurse-led telephone follow up (Telenursing ) on HbA1c among diabetic Patients. J Rafsanjan Univ Med Sci. 2010;9(3):175-84.

9. Hays RD, Kallich JD, Mapes DL, Coons SJ, Carter WB. Development of the kidney disease quality of life (KDQOL) instrument. Qual Life Res. 1994;3(5):329-38. doi: 10.1007/BF00451725. [PubMed: 7841967].

10. Yekaninejad MS, Mohammadi Zeidi I, Akaberi A, Golshan A, Pakpour A. Validity and reliability of the kidney disease quality of life - short form (KDQOL-SF ${ }^{\mathrm{TM}} 1.3$ ) in Iranian patients. J North Khorasan Univ Med Sci. 2012;4(2):261-72. doi: 10.29252/jnkums.4.2.261.

11. Taheri N. [Quality of life in hemodialysis patients]. J Sci Health Univ Shahroud Med Sci Health Serv. 2013;8(3). Persian.

12. Brunner LS, Smeltzer SCC, Bare BG, Hinkle JL, Cheever KH. Brunner \& suddarth's textbook of medical-surgical nursing. 13th ed. USA: Lippincott Williams \& Wilkins; 2010.

13. Gokal R, Khanna R, Krediet RT, Nolph K. Textbook of peritoneal dialysis. 4th ed. Germany: Springer Science \& Business Media; 2013.

14. Sadeghi T, Shahabinejad M, Derakhshan R, Balaii P. [Effect of nurseled telephone follow up (Telenursing ) on HbA1c among diabetic Patients].J Rafsanjan Univ Med Sci. 2010;9(3):175-84. Persian.

15. Sadeghishermeh M, Ghafouri F, Tadrisi SD, Tayyebi A. [The effect of follow-up care by telephone and shor massage services on patient's quality of life after cardiac valve replacement surgery]. Iran JCCN. 2013;6(1):65-72. Persian.

16. Victoria A, Maria T, Vasiliki M, Fotoula B, Kalliopi P, Evangelos F, et al. Adherence to therapeutic regimen in adults patients undergoing hemodialysis: The role of demographic and clinical characteristics. Int Arch Nurs Health Care. 2018;4(3). doi: 10.23937/2469-5823/1510096.

17. Salimi Ezzat L, Hanifi N, Dinmohammadi MR. [Effect of telephone consultation and follow-up on treatment adherence and hemodialysis adequacy in hemodialysis patients]. J Mazandaran Univ Med Sci. 2018;27(157):157-70. Persian.

18. Gallar P, Gutierrez M, Ortea O, Rodríguez I, Oliet A, Herrero JC, et al. Usefulness of telemedicine in the follow-up of peritoneal dialysis patients. Nefrologia. 2006;26(3):365-71.

19. Wells JR. Hemodialysis knowledge and medical adherence in African Americans diagnosed with end stage renal disease: Results of an educational intervention. Nephrol Nurs J. 2011;38(2):155-62. quiz 163. [PubMed: 21520694].

20. Chow SK, Wong FK. Health-related quality of life in patients undergoing peritoneal dialysis: Effects of a nurse-led case management programme. J Adv Nurs. 2010;66(8):1780-92. doi: 10.1111/j.13652648.2010.05324.x. [PubMed: 20557392]. 